\title{
Germline and somatic mutations of homologous recombination associated genes in non-serous ovarian cancer
}

Kentaro Sugino ${ }^{1}$, Kosuke Yoshihara ${ }^{1}$, Hirofumi Nakaoka², Nozomi Yachida ${ }^{1}$, Manako Yamaguchi', Yutaro Mori ${ }^{1}$, Risa Kudo ${ }^{1}$, Ryo Tamura $^{1}$, Kazuaki Suda1 ${ }^{1}$, Tatsuya Ishiguro ${ }^{1}$, Sosuke Adachi ${ }^{1}$, Masanori Isobe ${ }^{1}$, Masayuki Yamaguchi ${ }^{1}$, Masayuki Sekine ${ }^{1}$, Katsunori Kashima1 ${ }^{1}$, Teiichi Motoyama $^{3}$, Ituro Inoue ${ }^{2}$, and Takayuki Enomoto ${ }^{1}$

1. Department of Obstetrics and Gynecology, Niigata University Graduate School of Medical and Dental Sciences, Niigata, Japan.

2. Division of Human Genetics, National Institute of Genetics, Mishima, Japan.

3. Department of Molecular and Diagnostic Pathology, Niigata University Graduate School of Medical and Dental Sciences, Niigata, Japan.

\section{Introduction}

Homologous recombination deficiency (HRD) is a candidate of biomarker for predicting sensitivity of PARP inhibitors.

\section{Materials \& Methods}

- Subject: 207 ovarian cancer cases

- Sample: tumor and matched blood

- Sequence: Target-gene sequencing of 16 HR-associated genes.

- Patients receiving neoadjuvant chemotherapy were excluded in this study.
The prevalence of HRD in non-serous ovarian cancer $(\mathrm{OC})$ remains unclear.
Aim

To clarify the clinical significance of HRD in non-serous OC

Definition of pathogenic variants

Germline mutation

stopgain, frameshift indel, splicing

Somatic mutation

nonsynonymous SNV, stopgain, frameshift indel, non-frameshift indel, splicing

\section{Results}

\begin{tabular}{|c|c|c|c|}
\hline ATM & BARD1 & BRCA1 & BRCA2 \\
\hline BRIP1 & CHEK1 & CHEK2 & EMSY \\
\hline FANCL & NBN & PALB2 & RAD50 \\
\hline RAD51B & RAD51C & RAD51D & RAD54L \\
\hline
\end{tabular}

\begin{tabular}{lc}
\hline Characteristics & All (n = 207) \\
\hline Age (Mean \pm SD) & $56 \pm 11.7$ \\
Stage & \\
I & $109(52.7 \%)$ \\
II & $26(12.6 \%)$ \\
III & $59(28.5 \%)$ \\
IV & $13(6.3 \%)$ \\
\hline Histology & \\
HGS & $50(24.1 \%)$ \\
LGS & $6(2.9 \%)$ \\
CC & $99(47.8 \%)$ \\
EM & $39(18.8 \%)$ \\
MC & $13(6.3 \%)$ \\
\hline
\end{tabular}

Overall HR-associated gene mutations rate

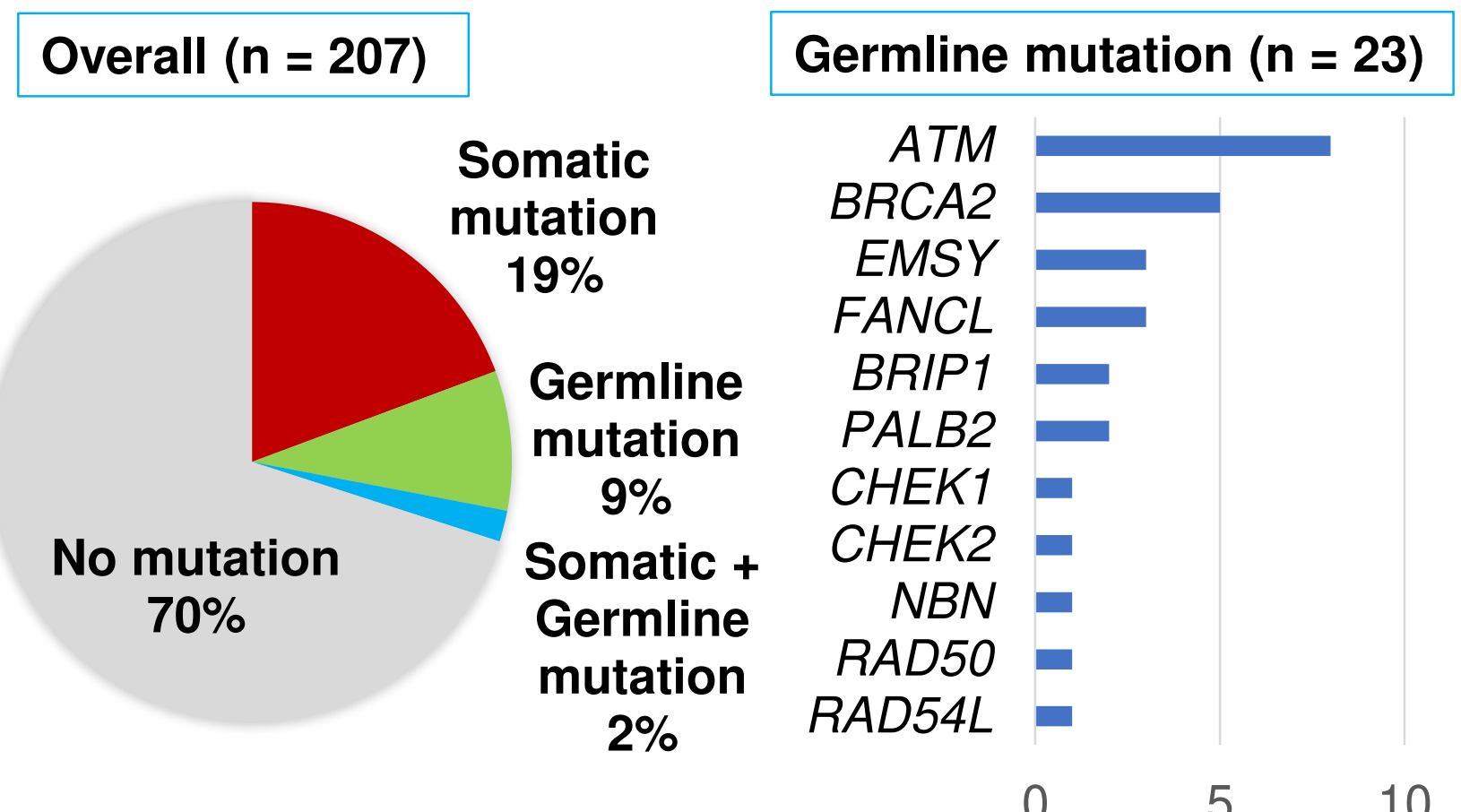

HGS: high-grade serous, LGS: low-grade serous, CC: clear cell, EM: endometrioid, MC: mucinous

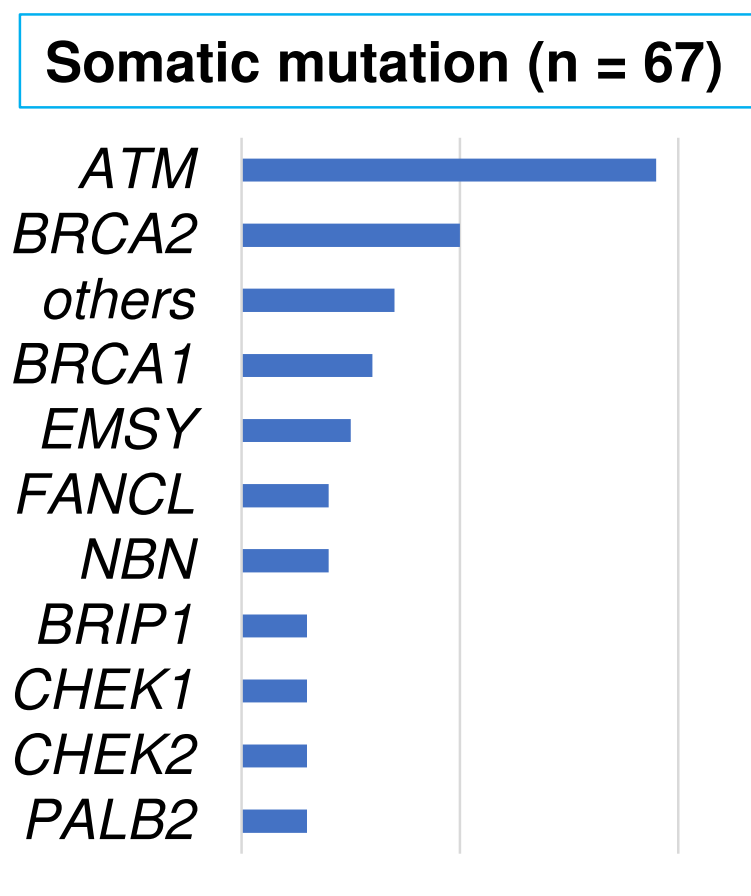

20
The frequency of HR-associated gene mutations per histology

\section{CC $27 \%$}

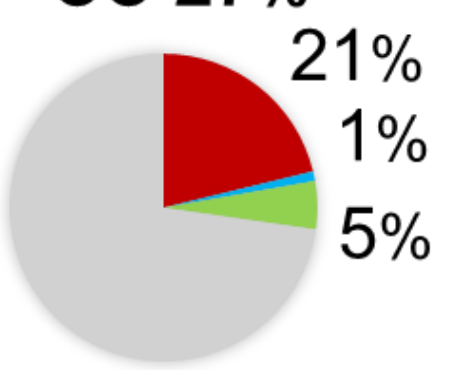

$\mathrm{n}=99$

HGS 44\%

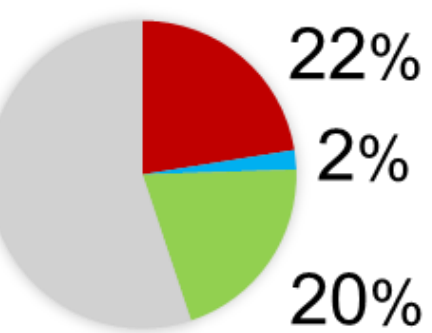

$\mathrm{n}=50$
EC 26\%

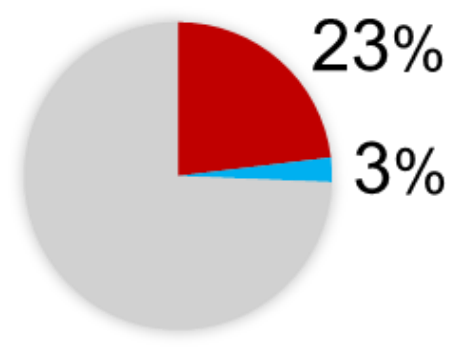

$\mathrm{n}=39$

LGS $17 \%$

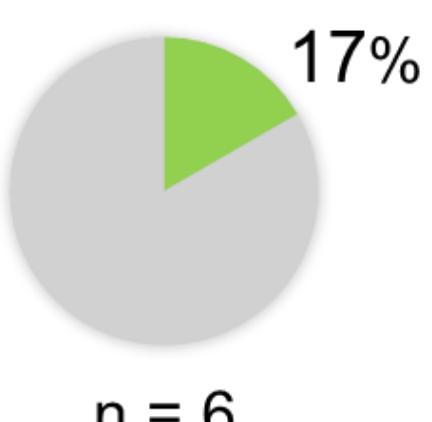

MC $15 \%$

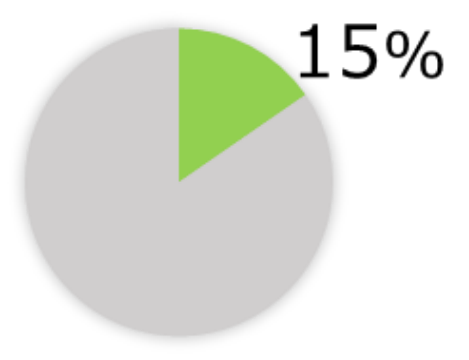

$n=13$
HR-associated gene mutations rate in CC

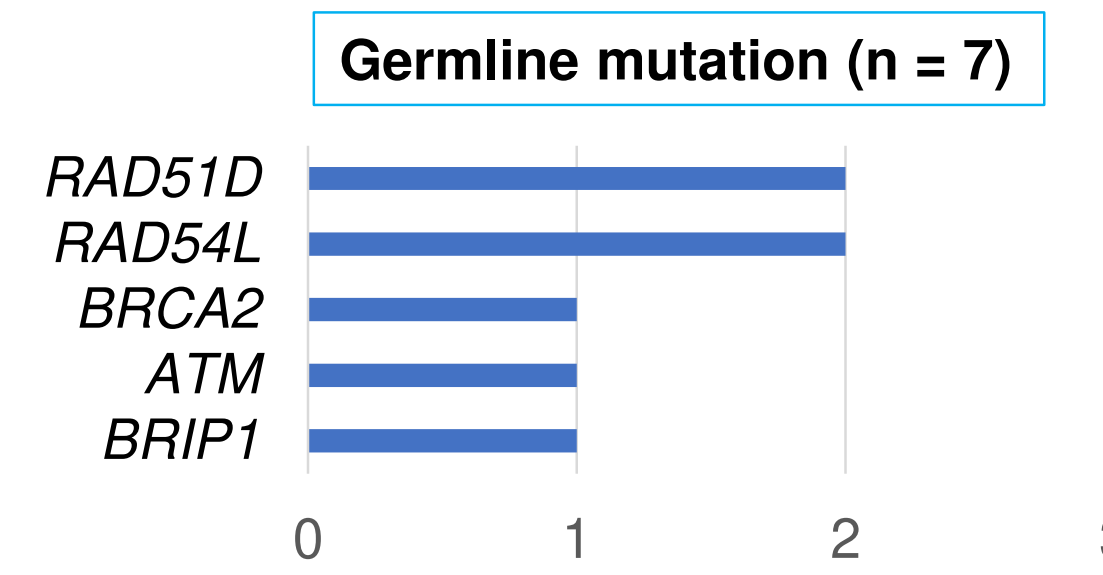

Somatic mutation

Somatic + Germline mutation

Germline mutation

No mutation

HRD was detected in each histologic type.

\section{Somatic mutation $(n=20)$}

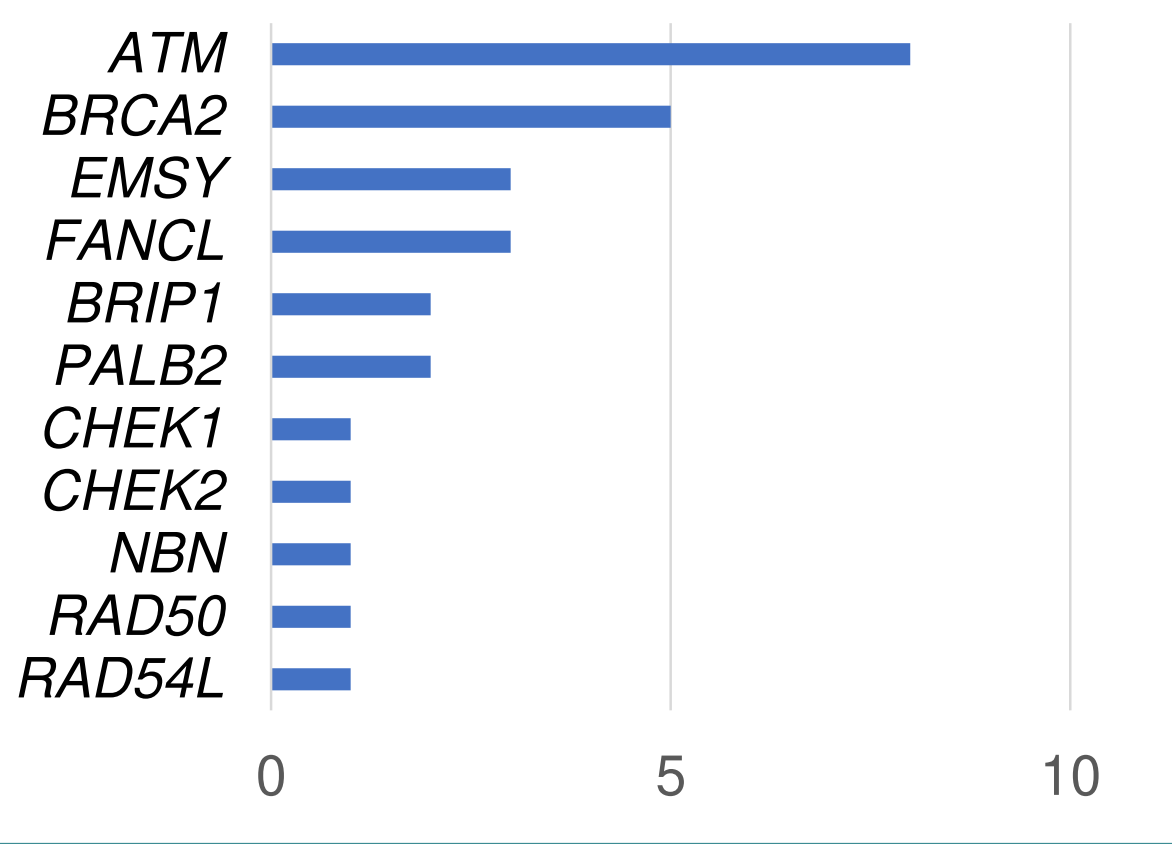

\section{Conclusion / Future Direction}

HRD was detected not only in HGS but also in other histologic types.
PARP inhibitors might give survival advantage to patients with not only HGS but also other histologic subtypes $\mathrm{OC}$ harboring HR-associated gene mutation. 